\title{
Repensando as Posições de Gênero na Atualidade: dos sólidos à constante fluidez
}

\author{
Júlio Cesar de Almeida Nobre \\ Professor Mestre (Psicossociologia de Comunidades e Ecologia Social - UFRJ) - \\ jcanobre@globo.com
}

\begin{abstract}
Resumo
O presente trabalho tem por objetivo estudar as posições de gênero como processamentos fluidos, a partir do entendimento da atualidade como imersa em um constante estranhamento que esvazia qualquer pretensão de um "algo em estado sólido e puro". Tal concepção se revela bastante diferenciada em relação a uma imagem moderna, na qual as relações de gênero se resumiriam a uma simples oposição hierárquica entre as masculino e feminino. Esse olhar oposicionista moderno registra uma dicotomia onde uma posição - fixa - se legitima perante a deslegitimação da outra - opositora e também fixa. A diferença não tem espaço senão como inimigo em um campo de batalha. Masculino e feminino, dentro de uma perspectiva moderna, configuram dessa forma, todo um jogo de oposições entre estruturas rigidamente delimitadas.
\end{abstract}

\section{Palavras-chave: Gênero, modernidade, redes e híbridos.}

\section{1- Introdução}

A Modernidade surge como movimento, a partir de meados do séc. XVII, apoiada nas "luzes da ciência" que instaura, em suas raízes, dicotomias entre natureza e cultura, sujeito e objeto, natural e artificial, etc. Dessa forma, surge o homem moderno, com seu olhar dividido, lentes que separam o mundo em entidades estanques. $\mathrm{O}$ eu de um lado e a natureza do outro, o sujeito de um lado e o objeto do outro.

Podemos observar, na contemporaneidade, que todas essas fronteiras erguidas à custa de muita história, de muito tempo, foram se naturalizando, se constituindo como a única possibilidade e calando todas as diferenças. Estamos adquirindo tal percepção devido ao intenso fluxo inter-fronteiras contemporâneo, misturas entre as diversas categorias modernas - vistas, até então, como rígidas. Essa fluidificação dos sólidos que passa a acontecer a todo momento traz ao convívio verdadeiros "monstros híbridos", misturas entre estruturas "não misturáveis” aos padrões modernos, que desconstroem todo o seu status de pureza, isto é, apontam para a impossibilidade da existência de sólidos em estado essencial.

Dentro de todo esse dinamismo que esvazia qualquer pretensão de um "algo em estado sólido e puro", pretendo estudar as posições de gênero como fluidos, diferentemente de uma imagem moderna, na qual as relações de gênero se resumiriam a uma simples oposição hierárquica entre as mulheres e os homens. Esse olhar oposicionista moderno registra uma dicotomia onde uma posição - fixa - se legitima perante a deslegitimação da outra - opositora e também fixa. A diferença não tem espaço senão como inimigo em um campo de batalha. Masculino e feminino, dentro de uma perspectiva moderna, configuram dessa forma, todo um campo de oposições entre estruturas rigidamente delimitadas. 
Para que possamos entender em que consiste a Modernidade e as mudanças atuais que a desestabiliza, faremos um percurso por autores contemporâneos como Bauman, Latour, Haraway, entre outros.

\section{2- A Modernidade: uma marcha obsessiva rumo à ordem}

Para Bauman (1999), a maior caracterização que pode ser dada àquilo que chamamos Modernidade é a de ser uma busca constante da ordem, de uma nomeação que atribui significações e segrega o mundo em um dentro e um fora. O que se vê é um constante movimento de construção de fronteiras que ordena o mundo dentro de limites e o transforma em algo familiar e esperado. Cria-se um mundo sólido, de entidades duradouras que permanecem "por aí". Essas entidades passam a ser consideradas naturais, como se estivessem estado no mundo desde sempre e neste mesmo formato.

O movimento moderno, ao se configurar como um soerguimento de muros estruturais que separam o dentro do fora, aquilo que é “algo" em contraposição "ao resto", pode ser considerado como uma batalha contra a ambivalência. Essa ambivalência seria a falência desses muros, uma falha na própria base da função ordenadora que visa segregar o mundo em entes sólidos e estáveis. O fora, através da ambivalência, invade o dentro estimulando o moderno a construir novas fronteiras que reordenem o mundo. Podemos ver, claramente, que a Modernidade, ao mesmo tempo em que teme a ambivalência como o seu algoz, tem nesta sua mola propulsora, seu motor em sua produção de ordenamentos que se querem cada vez mais exatos. O mundo moderno pode ser visto como um mundo em guerra contra a ambivalência, contra o caos que representa o flagelo da ordem, a morte, o fim da existência moderna.

A Modernidade, quando enrijece o mundo em dicotomias entre dentro e fora, reduz o fora a um mero negativo do dentro. Os incluídos são os detentores da regra do jogo, estão entre os "amigos", ao passo que os excluídos são simplesmente o reflexo borrado dos amigos, são os "inimigos" detentores de uma pura negatividade, aqueles que "são" somente em oposição àqueles que detém a condição de "realmente serem”. Os amigos são sujeito, são ação e os inimigos objeto, simples reação. O mundo moderno passa a se dividir entre "Nós" e “eles”, onde do lado do "eles" se enquadra todo o restante do que é “não-Nós”. Ser moderno é viver na expectativa de que essa dicotomia seja a história inteira, abarque a totalidade das coisas através de entidades sólidas, com “dentros” que se contrapõem a “foras”. O ser moderno é a existência de uma interioridade, uma singularidade intra-muros que se contrapõe a toda uma exterioridade que lhe serve de simples espelho para confirmar sua existência.

Apesar da pretensão moderna de abarcar a totalidade das coisas através da construção de ordenações que se apresentam como se fossem exatas, existem constantes “invasões” às fronteiras erguidas. O que escapa a toda essa construção moderna, segundo Bauman, é "o estranho", aquilo que se recusa a ser abarcado pela ordem, pelas categorias arquitetadas. O estranho mistura as estruturas modernas desmascarando-as em sua falsa pretensão de naturalidade, de universalidade. Sua simples entrada em cena aponta para outras possibilidades - conseqüentemente para a parcialidade de qualquer fronteira erguida - até então sequer passível de ser postulado. Novas portas são abertas em um mundo que já as conhecia todas. O dentro passa a se misturar ao fora. As categorias se misturam criando verdadeiros "monstros híbridos" que desmontam antigas fronteiras que se queriam naturais. $\mathrm{O}$ estranhamento traz inscrito em seu surgimento a falácia da natureza pura, de um mundo que “é e sempre será assim mesmo”. Toda fronteira moderna erguida deixa o estranho do lado de fora, à revelia de sua pretensão de querer abarcar a totalidade do mundo em sua simples dicotomia entre um dentro e um fora. 


\section{3- A Modernidade: uma dicotomia entre natureza e cultura}

Para Latour (1994), qualquer fronteira erguida, qualquer estabelecimento de uma ordem se constitui em um nó, uma amarração entre natureza e cultura. Aquilo que, para um moderno, consiste em uma Verdade puramente natural, atemporal, nada mais é do que um híbrido de natureza e cultura, nunca havendo uma pureza tanto de um lado quanto do outro. Sendo assim, ser moderno seria considerar dois tipos de prática, como sendo distintas, separadas entre si: respectivamente "a tradução" e a "purificação". A tradução seria um conjunto de práticas que mistura, estabelece mediações entre categorias, cria híbridos de natureza e cultura. A purificação, por sua vez, seria o conjunto de práticas que cria duas dimensões totalmente separadas entre si: de um lado a natureza e do outro a cultura, de um lado os não-humanos e do outro, os humanos.

Começaríamos a deixar de ser modernos no exato momento em que passássemos a considerar os dois conjuntos de práticas concomitantemente, visto que os modernos se sentiam especiais - ao ponto de romperem com os pré-modernos, considerados atrasados exatamente por "purificarem" a natureza, separando-a da cultura e, dessa forma, obtendo o "verdadeiro conhecimento". A Modernidade então, se caracteriza por uma dupla ruptura: primeiramente com o passado - ruptura temporal - criando um abismo entre este e o presente, e em segundo entre vencedores e vencidos, sendo os vencidos aqueles que estão no passado embriagado pelo mito, os "arcaicos"; e os vencedores, aqueles que estão no presente e são chamados de modernos.

Apesar dos modernos negligenciarem a existência dos híbridos em seu mundo, estes sempre existiram - sendo até mesmo estimulados - durante a Modernidade. As análises modernas sempre se situavam ora no lugar da cultura, ora no lugar do conhecimento, da natureza. Não existia interação possível, mistura entre essas dimensões e, conseqüentemente, não existia também, visibilidade alguma em relação aos híbridos de natureza e cultura, de conhecimento e política. O conhecimento verdadeiro, puro, passa a ser aquele advindo dos laboratórios, purificado pelo método científico que garantiria as "chaves" das leis da natureza. A purificação decanta tudo aquilo que é impureza - da ordem da cultura - das verdades da natureza. Separa-se portanto o humano do não-humano.

Dessa maneira, os modernos negligenciaram que todo esse formato na "abordagem da natureza" nada mais é que a própria "vida” do laboratório. A natureza "fala” através do “artifício” do laboratório. Não existe pureza a ser extraída da natureza. Ciência é cultura e natureza, é política e conhecimento, é mistura. As leis da natureza são fabricadas no laboratório, apesar de serem declaradas como que estando para além do mundo dos humanos. A modernidade, ao mesmo tempo que nega a existência dos híbridos de natureza e cultura em sua constituição, os produz com um afinco que beira a obsessão. Ao se deparar com um mundo dividido entre natureza/conhecimento de um lado e cultura/política do outro, os modernos negligenciaram também qualquer cuidado no trabalho de tradução. Para eles, como a natureza não tinha vínculo algum com a cultura, o trabalho de hibridação poderia se dar de forma cega, ocasionando uma grande instabilidade no mundo moderno.

\section{4- As Posições de Gênero na Modernidade}

Ao voltarmos nosso olhar para as posições de gênero durante a Modernidade, podemos ver que toda essa dicotomia entre natureza e cultura, toda essa busca insistente no sentido da ordem tinha lentes masculinas. Segundo Tarnas (2000), todo esse período poderia 
ser entendido como um fenômeno basicamente masculino, visto que toda a sua história foi construída por representantes desse gênero. O masculinismo ${ }^{1}$ então, teria se difundido, de tal forma, em todo o Ocidente moderno - tanto em homens quanto em mulheres - que promoveu a confusão entre a representação masculina e a própria noção de sujeito, assim como entre a representação feminina e a noção de objeto, igualando-a a natureza - que havia sido passivizada e disponibilizada à manipulação do sujeito Ocidental moderno. Ser um sujeito teria passado a ser então, a partir do séc. XVII, o mesmo que um típico Homem Ocidental Moderno. Mas sobre o que estamos falando quando nos referimos à um típico Homem Ocidental Moderno?

Para Nolasco (2001), a representação masculina tem estado intimamente ligada a caracterizações como virilidade, energia, força, potência, atividade, etc. A masculinidade não se reduziria ao sexo biológico, algo inato, mas seria uma conquista, uma vitória perante "situações adversas". Neste ponto de vista, a representação masculina se torna uma medalha a ser conquistada em um campo de batalha, conferindo honraria ao seu portador. Ser Homem é o mesmo que ser um herói. A batalha heróica masculina aponta para uma direção rigidamente delimitada rumo ao sagrado, a Verdade. De um lado está o divino e do outro, o mundano, o impuro. Ser masculino é trilhar esse percurso, povoado por obstáculos malévolos a serem superados, no sentido de um processo de purificação. O herói surge como aquele que alcança a transcendência ao se purificar do essencialmente mundano, comungando assim com o divino. A totalidade, a divina unificação seria arduamente buscada na posição masculina.

A representação masculina tem sido costurada com o tecido do herói, sendo este, o representante de toda a coletividade no percurso rumo ao essencialmente correto. Ao seguir no sentido da purificação daquilo que é considerado mundano, falho, o herói revela o caminho para o sagrado, delimitando suas fronteiras com o impuro. Ele, representa toda a coletividade nesse árduo caminho, sendo sua vitória, a vitória de todos, unindo a comunidade na Verdade. O herói masculino, através de suas ações masculinas, dita os parâmetros para o bem viver, o percurso rumo ao correto e o lugar da falha. Dessa forma, posições são cristalizadas, instaurando o silêncio e a invisibilidade perante seus alicerces que revelariam um caráter temporal.

Ao voltarmos nosso olhar para as concepções de Modernidade de Bauman e de Latour, podemos ver um sujeito moderno em uma batalha em defesa da ordem e contra o estranho - a ameaça incrustada no conceito de caos. Este, constantemente, invade as fronteiras erguidas, criando ambivalências que "obrigam" o nosso "ativo herói moderno" a defender a ordem, a buscar a purificação erguendo novos "muros", novas dicotomias que restabeleçam a "paz de espírito". A batalha masculinista moderna pode ser vista como uma busca heróica por uma "sagrada totalidade", onde as fronteiras entre o dentro e o fora permaneceriam solidamente erguidas e garantiriam a "inteireza" dos nativos do dentro. A grande ameaça é transformada, dessa forma, em um mero oposto do herói. Nada escaparia a essa divisão, que tem por objetivo um total controle sobre todas as coisas, solidificando estruturas, enrijecendo o devir ao transformá-lo no esperado. Tudo passa a ter "o seu devido lugar”.

Com as representações modernas de gênero não foi diferente. Para que se constituísse um sujeito moderno, ativo, solidificado em um dentro de pura positividade - a posição masculina - se construiu todo um fora passivo - a posição feminina - que por sua pura negatividade servia como espelho para a identidade do dentro. O Nós moderno parece ser uma posição masculina, o herói que encontra sua totalidade ao se purificar do errático, e o eles

\footnotetext{
${ }^{1}$ Tomo de empréstimo esse termo utilizado por Haraway (2000) na intenção de reforçar uma diferença entre ele e a noção de "machismo", muito associada ao sexo biológico.
} 
parece uma posição feminina, constituindo, ambas, um mundo masculinista, onde o dentro, os amigos dominam a regra do jogo designando fronteiras que os separam dos inimigos.

Os modernos acreditavam na naturalidade dessas posições, algo dado e imutável. Ao se fechar os olhos para os alicerces dessas posições - que desmascarariam essa concepção naturalista dos gêneros - cria-se todo um saber que se quer puro, isto é, decantado da cultura e por isso "verdadeiro". A natureza "falaria” através das posições fixas de gênero. Dessa forma, se a posição masculina foi "preenchida” com virilidade, energia, força, potência, atividade, etc (Nolasco, 2001), a posição feminina foi cristalizada como fraqueza, submissão, emotividade e incapacidade de pensamento abstrato (Haraway, 2000). Ser mulher, na Modernidade, era simplesmente o oposto de ser homem - a feminilidade era masculinista.

\section{5- A Atualidade: os sólidos se fluidificam}

Segundo Bauman, nos deparamos na atualidade com uma universalização do estranhamento, onde se torna cotidiano o convívio com tal experiência. O sujeito moderno, enclausurado dentro de fronteiras sólidas, se fluidifica na medida em que o indivíduo de hoje participa, simultaneamente, de diversos subsistemas concomitantes sem que um possa reivindicar alguma autoridade sobre os outros. Essa proliferação de subsistemas se deu, exatamente, a partir do movimento ordenador moderno, embalado pelo temor à ambivalência, que exigia novas fronteiras que a evitasse. As identidades, que até então eram sólidas, rígidas, pois os indivíduos tinham uma total experiência de pertencimento ao seu sistema - que os imputava identidades nativas - hoje se fluidificam na medida em que todo e qualquer sistema se apresenta como parcial. Os emaranhamentos de subsistema - suas inter-conexões - sempre irão ocasionar um estranhamento mútuo, apontando para uma outra possibilidade de existir e desmascarando toda a pretensão de solidez de qualquer sistema. Sempre existirá abertura e inconclusividade, ocasionando o que Fridman (2000) denomina "vertigens Pós-Modernas. Na ausência de uma unidade exterior que constitua o indivíduo em um completo nativo de um subsistema, o indivíduo contemporâneo deve se auto-construir a todo momento. A identidade, que na Modernidade era sólida, se liqüefaz. Toda ordem estabelecida deixa sempre algo de fora que lhe "sopra", a todo momento, instabilidade nas fronteiras. A ambivalência passa a ser uma constante, podendo-se conviver com múltiplas posições sem que uma exclua a outra, e sim complemente.

Segundo Latour parece que estamos nos reencontrando, atualmente, com a "velha matriz antropológica”, ao reconhecermos as práticas de tradução e purificação como não dicotômicas, simultâneas. Natureza e cultura são construídas concomitantemente. O que existe é uma rede de humanos e não-humanos que não pode ser reduzida a uma leitura unilateral tanto do lado do conhecimento quanto do lado da cultura. É uma rede coletiva de natureza/cultura. Esses híbridos de natureza/cultura, de humanos/não-humanos são vistos como artificiais e humanos demais para serem considerados naturais e não-humanos, ao passo que são também, naturais e não-humanos demais para serem denominados artificiais ou humanos. As fronteiras modernas entre humanos e não humanos, cultura e natureza se diluem e apontam para a falácia do puro.

\section{6- As Posições de Gênero na Atualidade}

Ao voltarmos nosso olhar para as posições de gênero na atualidade podemos perceber uma multiplicidade de perspectivas. Lentes dicotômicas passam a "dividir terreno" com lentes 
que se desfocaram e "tateiam algum caminho". No ponto de vista de Nolasco, estamos convivendo atualmente com a utilização da masculinidade como um "bode expiatório", como aquilo que pode ser considerado a encarnação do Mal. Sendo assim, surgem discursos de "virada de mesa”, discursos panfletários de emancipação de todas as minorias perante um “Todo-Poderoso" masculino “dominador”. Se no passado nos deparávamos com uma atitude que escravizava toda e qualquer parcialidade inscrevendo-a numa ordem totalizadora, hoje podemos perceber um esvaziamento do coletivo - associado historicamente ao herói masculino - e sua demonização em prol das minorias, das partes. O coletivo impediria a plena liberdade delas. O sagrado então vai de um pólo ao outro, encarnado em muitos discursos libertários progressistas das minorias - entre eles, alguns discursos feministas. Todos se sacralizam perante um grande Mal a ser combatido - a representação masculina, que gradativamente perde a voz, se tornando mero equívoco.

Essas minorias encontram fronteiras identitárias definidas nesta oposição entre certo e errado, dentro e fora, semelhante a definição do movimento moderno de Bauman. Apesar de não negarmos em hipótese alguma a importância de atitudes como essa no sentido de uma maior flexibilização de estruturas há muito cristalizadas, podemos concluir que a Modernidade continua viva em batalhas heróicas por um "lugar ao sol”. Este lugar é legitimado, através de um aniquilamento da diferença, uma instauração de negatividade em uma representação masculina para que, dessa forma, espelhe uma positividade do feminino. Tais atitudes contemporâneas se acreditam como que revelando a Verdade dos fatos por detrás do mito. Natureza e cultura continuariam, desta maneira, sendo instâncias dicotômicas. As grandes fronteiras se fragmentam em pequenas, porém extremamente sólidas que, de maneira oposta ao movimento de sacralização do todo, do coletivo, sacraliza as partes, os indivíduos.

Bauman já apontava que

“(...) a parte do mundo que adotou a civilização moderna como princípio estrutural e valor constitucional empenha-se em dominar o resto do mundo dissolvendo sua alteridade e assimilando o produto da dissolução” (Bauman, 1999: 246).

Podemos concluir, portanto, que nada é mais moderno do que "iluminados" movimentos emancipatórios de minorias em geral. Todos ganham uma positividade identitária as custas da negativização da figura homogeneizada em um "eles" - criado por um sujeito completamente estável. Os discursos emancipatórios, apesar de reconstruírem várias posições consideradas minoritárias, negaram uma reconfiguração da representação masculina, cristalizada como algo que atrapalha o caminho rumo ao uno - encarnado, muitas vezes, em um individualismo politicamente correto. Podemos perceber então, um "segundo turno" da Modernidade em um discurso anti-moderno, que rompe com o passado, se acreditando superior e detentor de verdadeiras “luzes”.

\section{7- Conclusão}

Segundo Haraway, uma excelente metáfora a ser utilizada para as posições de gênero na atualidade seria a dos ciborgues. Esses seres, habitantes das literaturas de ficção científica, conseguiriam hibridar humano e não-humano, cultura e natureza em sua própria "carne". Seriam híbridos, nascidos na parcialidade, que não poderiam seguir em um caminho rumo à uma bem-aventurança divina, uma totalidade, pois esta, para eles, não existiria. Sua mistura de natureza e cultura amarra as duas instâncias - antes dicotômicas - desmascarando qualquer 
pretensão de naturalidade "desamarrada” da cultura. Esta metáfora aponta para a inexistência de um puro artificial, assim como a de um puro natural. Sendo assim, os gêneros se tornam posições construídas historicamente que podem mudar com o tempo.

O ciborgue, para Haraway, seria uma criatura "pós-gênero", onde a dicotomia masculino/feminino - que estabelece posições naturais e rígidas - seriam desconstruídas como qualquer outra posição solidificada, podendo ser reconstruída de diversas formas. Os ciborgues, diferentemente do sujeito estável moderno que vivia "enclausurado" dentro de seu corpo, seriam redes de natureza/cultura, um emaranhado inter-conectado de humanos e nãohumanos. O ciborgue é, ao mesmo tempo, individual e coletivo: é um híbrido de ambos. A parte está interconectada com o todo e dele é expressão, da mesma forma que, por estar imersa no todo, atua nessa rede. Pensar gênero então, seria pensá-lo como um nó pertencente à rede onde natureza e cultura se constroem mutuamente, pois

"estamos dentro daquilo que fazemos e aquilo que fazemos está dentro de nós. Vivemos em um mundo de conexões - e é importante saber quem é que é feito e desfeito" (Kunzru, 2000: 36).

Com a metáfora do ciborgue, surge uma possibilidade de caminho onde as dicotomias modernas poderiam sair de cena, as dominações estruturadas enquanto oposições totalizantes poderiam deixar de existir, cedendo lugar à híbridos de natureza e cultura, de "fora" e de “dentro”. Os ciborgues povoam as fronteiras, não sendo totalmente nenhum dos dois lados. Um lado aponta para a parcialidade do outro. Falar em gênero ciborgue seria , exatamente, sair da batalha entre sexos - onde um lado afirma sua totalidade sobre o "cadáver" do outro. Estamos pisando em terreno "estranho", onde qualquer pretensão de totalidade rígida se fluidifica, desalojando todos os "plenamente nativos". Nunca se está totalmente em casa. Falar em gênero ciborgue é falar em gênero fluido.

Penso que se hoje, segundo Nolasco, é negada ao masculino uma representação pois este é colocado como "banalizado", passivizado, desprovido de potência, posto a serviço da positividade do feminino, o ciborgue de Haraway é uma alternativa. Não uma fusão de gêneros que colocaria outras categorias nos "bastidores do espetáculo”, mas uma produção sempre constante, irremediável tensão entre diferentes.

\section{8- Referências Bibliográficas}

BAUMAN, Z. Modernidade e ambivalência. Rio de Janeiro: Jorge Zahar, 1999.

FRIDMAN, L. C. Vertigens Pós-Modernas. Rio de Janeiro: Relume-Dumará, 2000.

HARAWAY, D. Manifesto ciborgue: ciência, tecnologia e feminismo-socialista no final do século XX. In: Silva, T. T. da (Org.). Antropologia do Ciborgue - as vertigens do pós-

humano. Belo Horizonte: Autêntica, pp. 37-129, 2000. 
KUNZRU, H. "Você é um ciborgue”: um encontro com Donna Haraway. In: Silva, T. T. da (Org.). Antropologia do Ciborgue - as vertigens do pós-humano. Belo Horizonte: Autêntica, pp. 19-36, 2000.

LATOUR, B. Jamais fomos modernos. São Paulo: Ed. 34, 1994.

NOLASCO, S. De Tarzan a Homer Simpson: banalização e violência masculina em sociedades contemporâneas ocidentais. Rio de Janeiro: Rocco, 2001.

TARNAS, R. A Epopéia do Pensamento Ocidental. Rio de Janeiro: Bertrand Brasil, 2000.

Informações bibliográficas:

Conforme a NBR 6023:2002 da Associação Brasileira de Normas Técnicas (ABNT), este texto científico publicado em periódico eletrônico deve ser citado da seguinte forma: NOBRE, J. C. A.. Repensando as Posições de Gênero na Atualidade: dos sólidos à constante fluidez. Cadernos UniFOA, Volta Redonda, ano 1, n. 2, nov. 2006. Disponível em: $<$ http://www.unifoa.edu.br/pesquisa/caderno/edicao/02/63.pdf > 